\title{
EM BUSCA DA SABEDORIA PERDIDA: RESENHA DE UM GUIA PARA OS PERPLEXOS
}

In search of the lost wisdom: review of a guide for the perplexed

Fábio Augusto Guzzo ${ }^{1}$

SCHUMACHER, E. F. Um guia para os perplexos. Tradução de Juliana Amato. Campinas, SP: Editora Auster, abril de 2020 (1 ${ }^{\mathrm{a}}$ edição), 180 p.

Economista de formação, autor de Small is Beautiful: A Study of Economics As If People Mattered (1973), considerado pela Times Literary Supplement um dos cem livros mais influentes desde a II Guerra Mundial, E.F. Schumacher publicou em 1977 Um guia para os perplexos, cujo objetivo é recuperar uma cosmovisão que, ao menos no Ocidente, foi esquecida graças ao avanço da ciência moderna. Podemos chamar essa concepção de Sabedoria Tradicional, ancorada, sobretudo, nas filosofias antiga e medieval e nas religiões milenares da humanidade.

O primeiro capítulo do livro - Os mapas filosóficos - fundamenta a necessidade de fazermos uma reavaliação da mentalidade contemporânea. Segundo Schumacher, "nossos mapas atuais dizem para esquecermos o que não pode ser provado; corremos o risco de perder o conhecimento das coisas superiores" (2020, p. 14). Assim, influenciados pelo mapa científico e materialista do mundo moderno, regiões inteiras da realidade desaparecem; somos, portanto, imunizados contra a pergunta pelo sentido da vida.

Um novo mapa deve ser construído: "vamos olhar para o mundo e tentar vê-lo por inteiro" (SCHUMACHER, 2020, p. 17). Para tanto, são estabelecidos quatro pontos de referência - as chamadas "quatro grandes verdades" (i) sobre o mundo, (ii) sobre os recursos do homem para conhecer o mundo, (iii) sobre o aprendizado homem e (iv) sobre viver a vida.

Uma distinção fundamental é estabelecida entre os tipos de mapa disponíveis: o mapa moderno é cético, traçando limites intransponíveis para a mente humana; o mapa tradicional, por sua vez, ainda que considere a fraqueza inerente à mente humana, deixa seus limites em aberto, pois há nesse mapa uma linha vertical, representativa das

\footnotetext{
${ }^{1}$ Bacharel, licenciado e mestre em Filosofia pela Universidade Federal do Rio Grande do Sul. Professor do Instituto Federal Catarinense - Campus Concórdia. ORCID iD: http://orcid.org/0000-0002-9717-4888
} 
dimensões qualitativas do "mais baixo" e "mais elevado". O homem, fechado no horizonte vertical, pode ter apenas mais do mesmo; com a possibilidade vertical, estamos abertos ao infinito: "A felicidade do homem é elevar-se" (SCHUMACHER , 2020, p. 24, grifo do autor).

O segundo capítulo - Níveis do ser - trata da grande verdade sobre o mundo: há uma cadeia do ser que se divide em quatro níveis: matéria, vida, consciência e autoconsciência. Existe uma diferença ontológica entre esses níveis, explicada pelo autor por meio de uma analogia com as dimensões geométricas: assim como, da elaboração de um ponto geométrico, jamais obteremos uma linha unidimensional, de uma linha uma superfície bidimensional e de uma superfície um sólido tridimensional, o ser humano, caracterizando-se pela autoconsciência, abarca os demais níveis do ser, sendo irredutível a eles.

Aqui é dado um primeiro passo no argumento contra o cientificismo materialista: a física e a química lidam com a matéria, ou seja, podem até lidar com o corpo portador de vida, mas não com a vida em si, que se constitui de algo mais que simples matéria. Por isso, as chamadas ciências da vida acabam por esquecer o fenômeno que, desde sua perspectiva materialista, é incompreensível, consequentemente reduzindo tudo à matéria. As humanidades, por sua vez, lidam com o fator consciência, mas não o distinguem da autoconsciência. Por esse motivo, estuda-se, por exemplo, o comportamento animal para compreender o comportamento humano, esquecendo do algo a mais que está presente apenas na humanidade. Desse erro intelectual, segundo o autor, origina-se a brutalização do ser humano: esquecemos de nossas capacidades superiores e passamos a ser tratados - e a viver - como animais ou mesmo máquinas. Salientemos que um passo adicional foi dado em nosso século XXI, passamos da confusão epistemológica para a confusão ontológica: fala-se já em trans-humanismo, hibridismo: queremos isso?

Cabe observar que nossa finalidade está inscrita em nossa natureza, mas ela não vem pronta. Schumacher nos dá, assim, uma caracterização teleológica do ser humano: "As forças da autoconsciência são, essencialmente, potencialidades ilimitadas, e não atualidades. Elas devem ser desenvolvidas e 'atualizadas' por cada ser humano individual que queira tornar-se verdadeiramente humano, ou seja, uma pessoa" (SCHUMACHER, 2020, p. 35, grifo do autor). Noto que, dessa concepção, deriva-se uma possível filosofia da educação: se tratarmos, em nossas escolas, apenas da sobrevivência, das habilidades necessárias ao "mundo do trabalho", jamais desenvolveremos nossa finalidade intrínseca. 
O terceiro capítulo - Progressões - analisa o movimento que percorre os quatro níveis do ser. Uma das características desse movimento é a passagem da passividade para a atividade. No ser humano, atividade da autoconsciência ocorre por meio da vontade, cuja independência em relação à matéria - o nível mais passivo - nos garante a liberdade. Ademais, só existe liberdade quando existe interioridade, o reduto humano que nos isola da necessidade presente no mundo físico.

A ascensão na dimensão vertical do ser vai sempre em direção à integridade, ou seja, à unidade interna que permite ao homem agir e não apenas sofrer ações. Simultaneamente, passa-se da visibilidade para a invisibilidade: nossa personalidade encontra-se no mais secreto âmbito de nosso ser. Notamos, aqui, ecos das filosofias antigas: também o diálogo socrático e a confissão agostiniana identificavam na interioridade humana a origem do conhecimento.

Reconhecendo a nossa invisibilidade, Schumacher acrescenta, é natural que aceitemos a existência de outros âmbitos invisíveis para além do ser humano: "homo non proprie humanus est sed superhumanus est" (2020, p. 53), essa definição escolástica do homem, da qual a estrutura hierárquica do ser é uma pressuposição, já apontava para a capacidade humana da autotranscendência. Sendo assim, quanto mais profundo o mergulho na interioridade, maior será o nosso mundo, nossas possibilidades cognitivas e existenciais. O homem moderno, contudo, preso pela perspectiva materialista, conhece apenas aquilo que é visível, aquilo que pode ser contado, pesado e medido pelas ciências físicas. Esses limites intelectuais determinarão suas possibilidades vitais. Como diz Schumacher, "seu nível de ser atrai a sua vida" (2020, p. 50).

Se a premissa das "progressões" estiver correta, percebamos a urgência em reconstruir o mapa tradicional. Percebamos também como a filosofia não consiste apenas em teorias sem consequências práticas. Como nos ensina Luc Ferry em Aprender a viver (cf. 2010, pp. 25-8), a teoria vem antes da sabedoria: essa pode ser alcançada somente se conhecermos, previamente, o nosso campo de ação. Assim, é a nossa cosmovisão que possibilitará a nossa felicidade.

O quarto capítulo - Adaequatio I - investiga o princípio de adequação, a segunda grande verdade do mapa a ser reconstruído pelo autor. Tal princípio é expresso na máxima de Plotino: "Saber exige o órgão adequado ao objeto", ou seja, existe uma correspondência entre os níveis de ser e níveis da capacidade cognitiva do homem. Assim, não podemos conhecer um nível superior por meio de uma capacidade inferior. Por consequência, há muitas diferenças entre os indivíduos, pois falta a muitos a adequação 
intelectual aos objetos superiores: "a sua fé exclui a possibilidade dessa existência" (SCHUMACHER, 2020, p. 61).

Diagnostiquemos o nosso tempo a partir das ideias lançadas por Schumacher: se o materialismo rebaixou a tal ponto um certo número de pessoas, obviamente não há solução para o debate entre ciência e religião. É possível que a atual rejeição à última se deva não a um fator racional, mas a um fator cultural, a uma mera incapacidade de vermos aquilo que os antigos viam. Recorrendo a Thomas Kuhn, podemos dizer que nosso paradigma é diferente. Afinal, sem um objeto em comum, de que modo poderia haver um confronto entre as culturas científica e religiosa? É uma luta em que cada golpe perde-se no ar, em que só se pode atingir um adversário imaginário.

Percebamos como interligam-se os âmbitos da ontologia, da epistemologia, da psicologia e da ética. Schumacher enfatiza o papel da fé porque ela "possui uma verdade oculta” (2020, p. 61). Qual é o problema do materialista, então? Ele não tem a fé adequada. É até mesmo verossímil, eu diria, estar diante de um nível superior do ser e ainda assim não vê-lo: sem a fé, sem o arcabouço intelectual - sem o mapa adequado para nos guiar - simplesmente não reconheceremos a distinção entre o inferior e o superior. $\mathrm{O}$ conhecimento não é apenas um ato intelectual, mas também um ato moral: cabe sempre ao homem a decisão de não crer.

No quinto capítulo - Adaequatio II - são abordadas as causas e consequências da cosmovisão científica. O modelo matemático do mundo buscou, por exemplo, neutralizar a subjetividade do observador. Para tanto, resta à ciência apenas a quantidade, perdendo de vista toda a dimensão qualitativa da experiência humana. O conhecimento matemático da natureza produziu, além disso, uma ciência da manipulação: limitado ao mundo material, restou ao homem, como objetivo máximo de seus esforços intelectuais, modificá-lo conforme seus interesses pessoais. Note-se aqui a contradição dessa atitude: desqualificar a subjetividade humana naquilo que ela tem de universal - a experiência comum - para entronizá-la novamente, agora naquilo que ela tem de arbitrário.

O capítulo seis - Os quatro campos do saber - campo um - inicia a análise da terceira grande verdade: os caminhos do nosso aprendizado no mundo. A reconstituição de uma visão abrangente da realidade se daria a partir de duas dualidades: eu/mundo e aparência exteriores/experiência interiores, que resultam em quatro perguntas: (i) como me sinto?, (ii) como você se sente?, (iii) o que eu aparento? e (iv) o que você aparenta?

A primeira pergunta refere-se ao nível da autoconsciência, que é analisada de acordo com a psicologia tradicional. As tradições espirituais do taoísmo, do budismo e 
do cristianismo, por exemplo, apontam para o mundo interior como o sendo a dimensão onde se realiza a autotranscendência humana. A exploração de nossa interioridade requer o poder da atenção, e Schumacher pergunta-se, nos anos 70, se ainda tínhamos o domínio dela. Passados cinqüenta anos, em meio à enxurrada de informações proporcionadas pela internet, a pergunta torna-se ainda mais pertinente.

Na tradição, o método budista da atenção plena, o método cristão da oração incessante e o método indiano da yoga são caminhos propostos para a intensificação do que temos de superior: "no nível humano do ser, a invisibilia possui uma força infinitamente maior que a visibilia..." (SCHUMACHER, 2020, p. 98). Desligar-se dos conteúdos empíricos e apegar-se à autoconsciência: assim atingiremos o "ego puro", o “eu”, o "vazio" ou o "poder divino" (cf. SCHUMACHER, 2020, p. 103).

Saber o que os outros sentem - o segundo campo do saber, tema do sétimo capítulo - envolve duas traduções: na primeira, o falante deve traduzir seu pensamento em formas visíveis; na segunda, o ouvinte deve traduzir esses sinais em pensamento seu. Sob essas duas condições é possível um "encontro de mentes”. Basicamente, a sabedoria tradicional ensina que o conhecimento dos outros depende do autoconhecimento. Assim, ele deve vir antes: devo conhecer-me interiormente, descobrir e atualizar minhas capacidades superiores para conseguir traduzir os outros como pessoas e não como animais ou máquinas. Ao final do capítulo, como exemplo de pessoas que atingiram o auge do desenvolvimento interior, são brevemente narradas as vidas de Jakob Lorber, Edgar Cayce e Therese Neumann, que, transcendendo o nível da humanidade comum, tornaramse verdadeiramente humanos.

No terceiro campo do saber - assunto do oitavo capítulo -, trata-se de "conhecer a mim mesmo como fenômeno objetivo", o que envolve equilibrar nossas intenções (invisibilia) e nossas ações (visibilia). A meta é nos vermos com os olhos dos outros, um exercício de humildade que requer a auto-observação acrítica. Necessário para a vida em sociedade, o altruísmo é desenvolvido após eu conseguir perceber-me como uma pessoa entre outras, com todas as suas imperfeições e contradições.

O nono capítulo analisa o quarto campo do saber - a aparência do mundo à nossa volta. Ela pode ser objetivo de dois tipos de ciência: (i) as ciências instrucionais (caracterizadas pela manipulação de seus objetos) baseiam-se nos aspectos inanimados da natureza; (ii) as ciências descritivas (caracterizadas pela compreensão), por outro lado, baseiam-se nos níveis superiores do ser. Schumacher observa o seguinte: quanto mais 
maduro o objeto da ciência, ou seja, quando mais livre e, portanto, mais imprevisível, menos madura é a ciência correspondente.

Ou seja, alcançamos a exatidão científica ao preço da arbitrariedade. Para as ciências instrucionais não há distinção entre epistemologia e ontologia (cf. SCHUMACHER, 2020, p. 140), ou seja, não há nada para além daquilo que a ciência determinou como passível de ser investigado por seus próprios métodos. Num mundo dominado por esse tipo de ciência, teríamos aquilo que Ortega denunciou em seu livro Lições de Metafísica: estamos substituindo a experiência primária pela experiência secundária (cf. Ortega y Gasset, 2019).

Além disso, as ciências da manipulação estariam, através da tecnologia delas decorrentes, moldando nossas vidas em dois sentidos: inicialmente, nossa própria atenção passa a importar-se somente com os aspectos manipuláveis da natureza, instaurando uma mentalidade exclusivamente utilitarista; em segundo lugar, o próprio ser humano passa a ser tratado como um objeto manipulável pela ciência, que determina as regras a serem preenchidas pelo indivíduo.

Seguindo os passos de Josef Pieper, a tese de Schumacher poderia ser complementada no seguinte sentido: se a concepção matemática da realidade trouxe consigo o predomínio das ciências da manipulação, paralelamente consolidou-se o mundo do trabalho e a noção de que "o ser humano é funcionário, mesmo nas formas mais elevadas de sua atuação" (PIEPER, 2020, p. 63). Consequentemente, são aceitáveis em nossa sociedade apenas as atividades úteis. Sem a atividade inútil da contemplação, o ócio enquanto "silêncio que condiciona a percepção da realidade (PIEPER, 2020, p. 71) torna-se impensável. Na era do streaming, não seria correto dizer que o entretenimento tomou o lugar da contemplação? Enfim, notemos a força do mapa a ser combatido por Schumacher: ele envolve toda uma ontologia que transforma até mesmo um estado originariamente teológico - o ócio, a contemplação - em necessidade a ser satisfeita pelo mercado.

No décimo e último capítulo - Dois tipos de problema - afirma-se que "viver significa lutar [...] resolver problemas" (SCHUMACHER, 2020, p. 155, grifo do autor), que podem ser de dois tipos: existem os problemas convergentes - relativos aos aspectos mortos da realidade - em que naturalmente as respostas levam para o mesmo destino; contudo, "a vida é maior que a lógica" (SCHUMACHER, 2020, p. 158), e os problemas divergentes - relativos aos aspectos livres da realidade - não podem ser solucionados pela lógica linear, segundo a qual, se uma resposta é correta, sua contrária não o é. Por 
exemplo: na educação temos a tensão entre liberdade e obediência, ambas necessárias para tal atividade. $\mathrm{Na}$ vida prática, tais problemas só podem ser resolvidos pelas forças superiores do homem, tais como o amor, a empatia, a compreensão e a compaixão. É na tensão dos opostos, afirma Schumacher, que a autoconsciência intensifica-se, impulsionase para o alto e dissolve a oposição.

É nesse sentido que algumas das páginas finais do livro são dedicadas à arte, cuja importância é a de nos despertar para "aquilo que realmente desejamos fazer, mas nos esquecemos" (SCHUMACHER, 2020, p. 167, grifo do autor). Trata-se de uma jornada humana, impossível de ser empreendida por um computador; portanto, é a arte, e não a lógica ou a ciência - ao menos não a ciência instrucional - que pode nos servir de ferramenta para enfrentarmos os problemas divergentes.

Encontramos, em Um guia para os perplexos, sobretudo uma alternativa para todos aqueles que sentem algo de errado em nossa sociedade tecnológica, cada vez mais online, cada vez mais veloz e barulhenta. Temos em abundância, mas um mal-estar permanece: o sucesso material não trouxe consigo a felicidade. Muitas vezes encontramos no mercado várias opções para preencher nossa busca espiritual, mas como distinguir a espiritualidade autêntica da falsa? Se o leitor pensa, como Schumacher, que "[a] experiência moderna da vida sem religião fracassou" (2020, p. 177, grifo do autor), ele tem em mãos um novo mapa para reorientá-lo em seu caminho.

\section{REFERÊNCIAS}

FERRY, Luc. Aprender a viver. Tradução de Véra Lucia dos Reis. $2^{\mathrm{a}}$ ed. Rio de Janeiro: Objetiva, 2010.

ORTEGA Y GASSET, José. Lições de metafísica. Tradução de Felipe Denardi. Campinas: Vide Editorial, 2019.

PIEPER, Josef. Ócio e contemplação. Tradução de Alfred J. Keller. Campinas, SP: Kírion, 2020.

SCHUMACHER, E. F. Um guia para os perplexos. Tradução de Juliana Amato. Campinas, SP: Editora Auster, abril de 2020 ( $1^{\text {a }}$ edição). 